\title{
Site Selective Binding and Dual Mode Recognition of Serum Albumin by a Squaraine Dye
}

\author{
Vadakkancheril S. Jisha, Kalliat T. Arun, Mahesh Hariharan and Danaboyina Ramaiah* \\ * To whom correspondence should be addressed at: \\ Photosciences and Photonics \\ Regional Research Laboratory (CSIR) \\ Trivandrum 695 019, INDIA \\ Tel: (+91) 4712515362 \\ Fax: (+91) 471 2490186, 2491712 \\ E-mail: rama@ csrrltrd.ren.nic.in or d_ramaiah@ rediffmail.com
}

\section{SUPPLEMENTARY SUPPORTING INFORMATION}

Experimental and calculation details, Table S1 and Figures S1-S9 showing photophysical, circular dichroism (CD) and cyclic voltammetry (CV) properties of squaraine dye (SQ) in presence and absence of bovine serum albumin (BSA), dansylamide (DNSA) and dansylproline (DP).

\section{Experimental section and calculation of association constants $\left(K_{\text {ass }}\right)$, change in free energy $(\Delta G)$ and non-radiative decay rate constant $\left(k_{\mathrm{nr}}\right)$}

General experimental techniques. The electronic absorption spectra were recorded on a Shimadzu UV-VIS-NIR spectrophotometer. Fluorescence spectra were recorded on a SPEX-Fluorolog F112X spectrofluorimeter. Cresyl violet $\left(\Phi_{\mathrm{f}}=0.52\right)$ in methanol was used as the standard. The quantum yields of fluorescence were calculated using the equation 1,

$$
\Phi_{\mathrm{u}}=\frac{\mathrm{A}_{\mathrm{s}} \mathrm{F}_{\mathrm{u}} \mathrm{n}_{\mathrm{u}}^{2}}{\mathrm{~A}_{\mathrm{u}} \mathrm{F}_{\mathrm{s}} \mathrm{n}_{\mathrm{s}}{ }^{2}} \Phi_{\mathrm{s}}
$$

where, $A_{s}$ and $A_{u}$ are the absorbance of standard and unknown, respectively. $F_{s}$ and $F_{u}$ are the areas of fluorescence peaks of the standard and unknown and $n_{s}$ and $n_{u}$ are the refractive indices of the solvents used for the standard and unknown, respectively. $\Phi_{s}$ and $\Phi_{u}$ are the fluorescence quantum yields of the standard and unknown compounds. Cyclic voltammograms (CV) were recorded on Bioanalytical Systems Inc., BAS-CV50W cyclic voltammeter. Circular dichroism (CD) spectra were recorded on Jasco Corporation, J-810 spectropolarimeter. Doubly distilled water was used in all the studies. All experiments were carried out at room temperature $\left(25 \pm 1{ }^{\circ} \mathrm{C}\right)$, unless otherwise mentioned.

Scanning Electron Microscopy (SEM). BSA solution in the absence and presence of SQ was placed on sample studs and coated with gold by ion sputtering. SEM images were 
obtained on a JEOL $5600 \mathrm{LV}$ scanning electron microscope with an accelerating voltage of $15 \mathrm{kV}$.

Atomic Force Microscopy (AFM). Samples for the imaging were prepared by drop casting the BSA solution in the absence and presence of SQ on freshly cleaved mica at the required concentrations. AFM images were recorded under ambient conditions using a Digital Instrument Multimode Nanoscope IV operating in the tapping mode regime. Micro-fabricated silicon cantilever tips (MPP-11100-10) with a resonance frequency of $299 \mathrm{kHz}$ and a spring constant of $20-80 \mathrm{Nm}^{-1}$ were used. The scan rate varied from 0.5 to $1.5 \mathrm{~Hz}$. AFM section analysis was done offline.

Calculation of association constant $\left(\mathrm{K}_{\text {ass }}\right)$. The intrinsic binding constant $\left(\mathrm{K}_{\text {ass }}\right)$ was determined from the half reciprocal plot of $\mathrm{D} / \Delta \varepsilon_{\text {ap }}$ vs $\mathrm{D}$, where $\mathrm{D}$ is the concentration of BSA, $\Delta \varepsilon_{\mathrm{ap}}=\left[\varepsilon_{\mathrm{a}}-\varepsilon_{\mathrm{F}}\right]$ and $\Delta \varepsilon=\left[\varepsilon_{\mathrm{b}}-\varepsilon_{\mathrm{F}}\right]$. The apparent extinction coefficient, $\varepsilon_{\mathrm{a}}$, is obtained by calculating $\mathrm{A}_{[\mathrm{obsd}]} /[\mathrm{SQ}] . \varepsilon_{\mathrm{b}}$ and $\varepsilon_{\mathrm{F}}$ correspond to the extinction coefficient of the bound form of SQ and the extinction coefficient of free SQ, respectively. The data were fitted to equation $2,{ }^{1}$ with a slope equal to $1 / \Delta \varepsilon$ and a y-intercept equal to $1 / \Delta \varepsilon \mathrm{K}_{\mathrm{ass}}$. $\varepsilon_{\mathrm{b}}$ was determined from $\Delta \varepsilon$, and $\mathrm{K}_{\text {ass }}$ was obtained from the ratio of the slope to the $\mathrm{y}$-intercept.

$$
\frac{\mathrm{D}}{\mathrm{D} \varepsilon_{\mathrm{ap}}}=\frac{\mathrm{D}}{\mathrm{D} \varepsilon}+\frac{1}{\mathrm{D} \varepsilon \mathrm{K}_{\mathrm{ass}}}
$$

Calculation of change in free energy $(\Delta \mathrm{G})$. Change in free energy $(\Delta \mathrm{G})$ associated with the complexation between SQ and BSA, was determined using the equation $3,{ }^{2}$

$$
\Delta \mathrm{G}=-2.303 \mathrm{RT} \log \mathrm{K}_{\mathrm{ass}}
$$

where $\mathrm{K}_{\text {ass }}$ is the binding constant.

Calculation of non-radiative decay rate constant $\left(k_{n r}\right)$. In order to calculate the nonradiative decay rate constant $\left(k_{\mathrm{nr}}\right)$, the equation 4 was used, ${ }^{3}$

$$
k_{\mathrm{nr}}=k_{\mathrm{r}}\left[\frac{1}{\Phi_{\mathrm{f}}}-1\right]
$$

where $k_{\mathrm{r}}$ is radiative decay rate constant, $\Phi_{\mathrm{f}}=$ fluorescence quantum yield of SQ. Radiative decay rate constant $k_{\mathrm{r}}$ can be determined using the equation 5,

$$
k_{\mathrm{r}}=\frac{\Phi_{\mathrm{f}}}{\tau_{\mathrm{f}}}
$$

where $\tau_{\mathrm{f}}$ is lifetime of $\mathrm{SQ}$ and $\Phi_{\mathrm{f}}=$ fluorescence quantum yield of $\mathrm{SQ}$.

\section{References}

1) Kumar, C. V.; Buranaprapuk, A. Angew. Chem., Int. Ed. Eng. 1997, 36, 2085.

2) Urien, S.; Nguyen, P.; Berlioz, S.; Bree, F.; Vacherot, F.; Tillement, J. Biochem. J. 1994, 302, 69.

3) Kamat, P. V.; Das, S.; Thomas, K. G.; George, M. V. J. Phys. Chem. 1992, 96, 195. 
Table S1. Photophysical properties and association constant $\left(\mathrm{K}_{\mathrm{ass}}\right)$ of SQ in presence and absence of bovine serum albumin (BSA). ${ }^{\mathrm{a}}$

\begin{tabular}{ccrrrr}
\hline & $\begin{array}{c}\text { absorption } \\
\lambda_{\max }, \mathrm{nm}\end{array}$ & $\begin{array}{c}\text { emission } \\
\lambda_{\text {max }}, \mathrm{nm}\end{array}$ & $\Phi_{\mathrm{f}}$ & \multicolumn{1}{c}{} & $\mathrm{K}_{\mathrm{ass}}, \mathrm{M}^{-1}$ \\
\hline $\mathrm{SQ}$ & 584 & 600 & 0.0014 & $0.121 \mathrm{~ns}(100 \%)$ & - \\
$\mathrm{SQ}+\mathrm{BSA}^{\mathrm{b}}$ & 601 & 618 & 0.11 & $0.5 \mathrm{~ns}(60 \%)$ and & $1.4 \pm 0.1 \times 10^{6}$ \\
& & & & $1.5 \mathrm{~ns}(40 \%)$ & \\
\hline
\end{tabular}

${ }^{\mathrm{a}}$ Average of more than three experiments; ${ }^{\mathrm{b}} 7 \mu \mathrm{M}$ of BSA, biexponential decay.

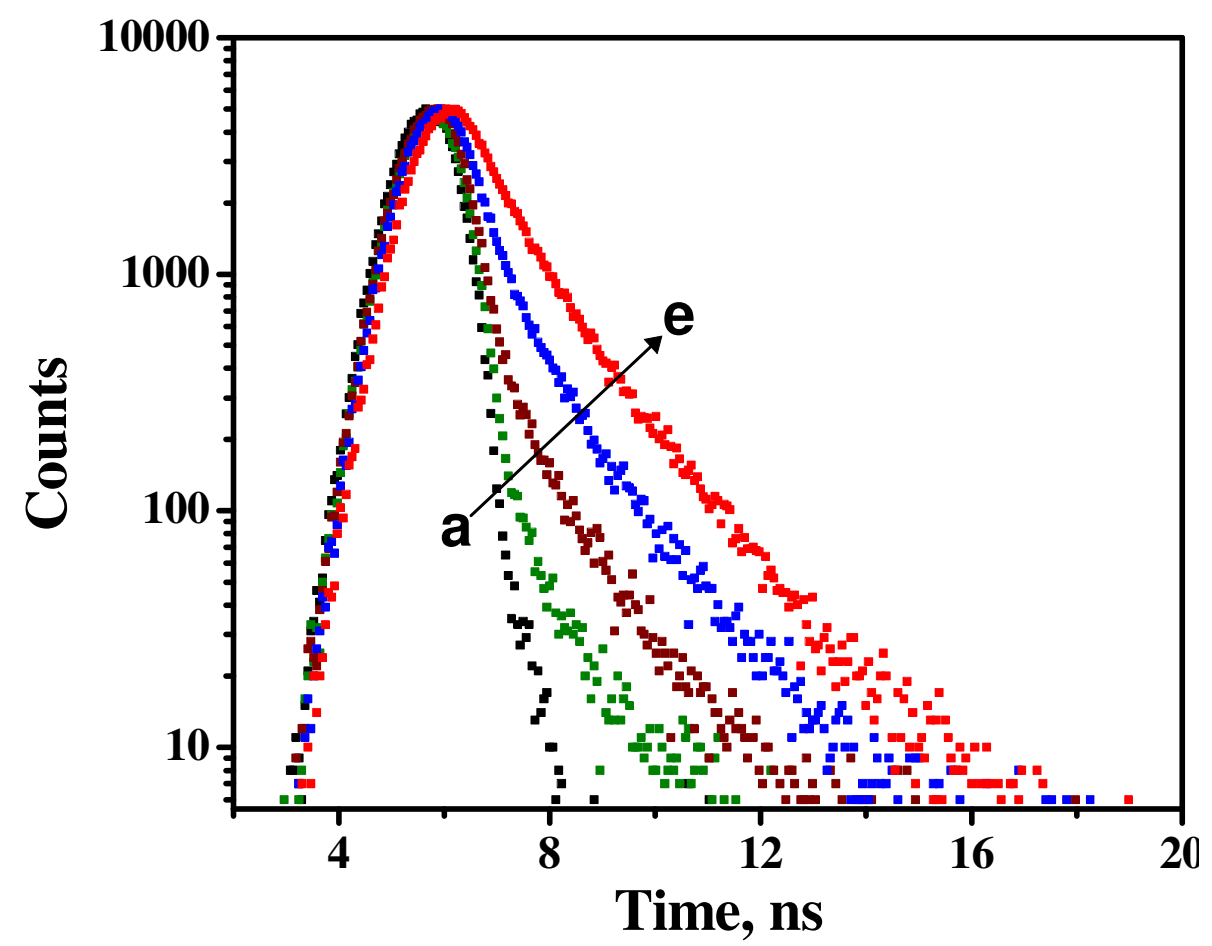

Figure S1. Time-resolved fluorescence decay of SQ $(3 \mu \mathrm{M})$ with the increase in addition of BSA. [BSA] a) 0 , b) 0.18 , c) 0.37 , d) 0.75 and e) $7 \mu \mathrm{M}$. 


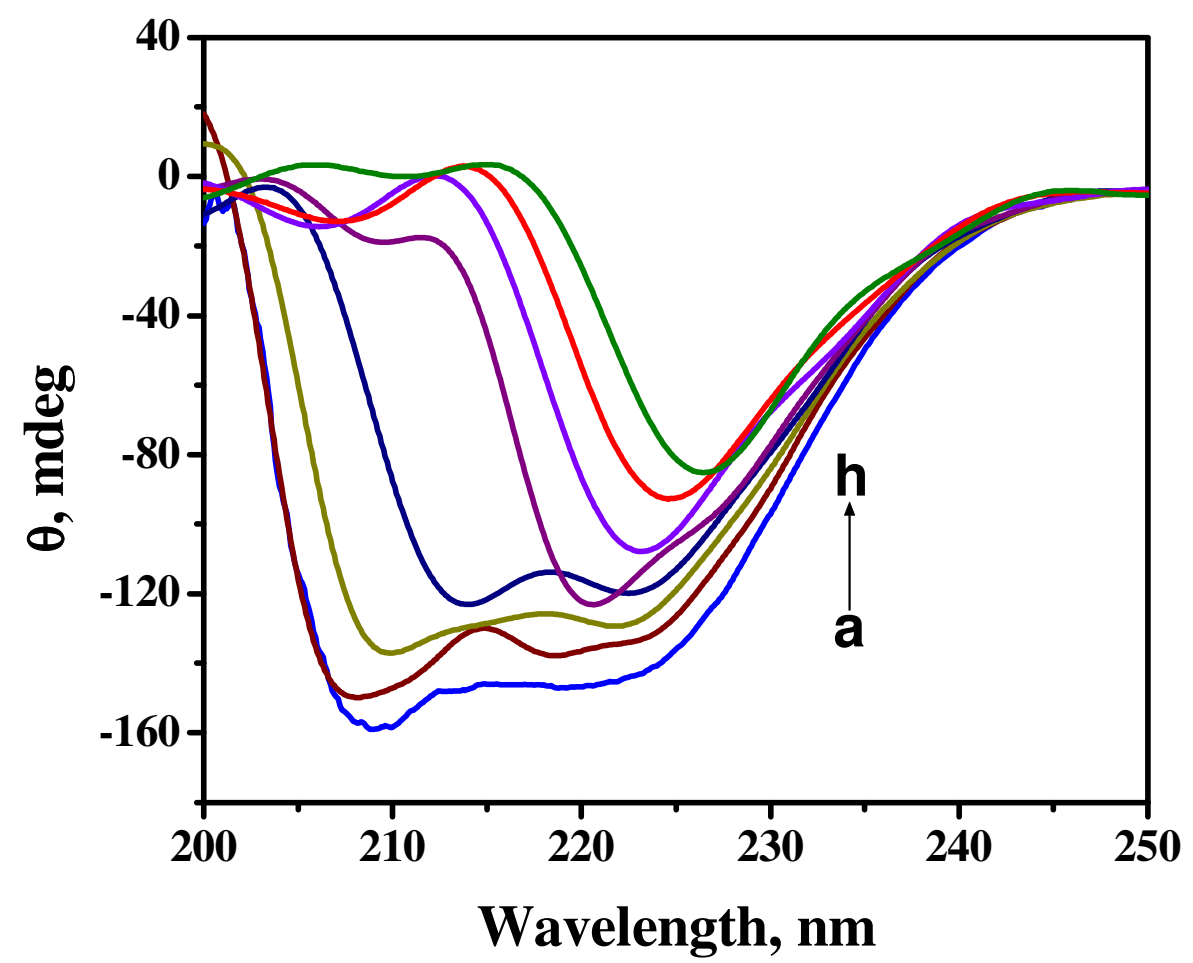

Figure S2. Circular dichroism (CD) spectra of BSA $(0.8 \mu \mathrm{M})$ with increase in addition of SQ. [SQ] a) 0 and h) $78 \mu \mathrm{M}$.

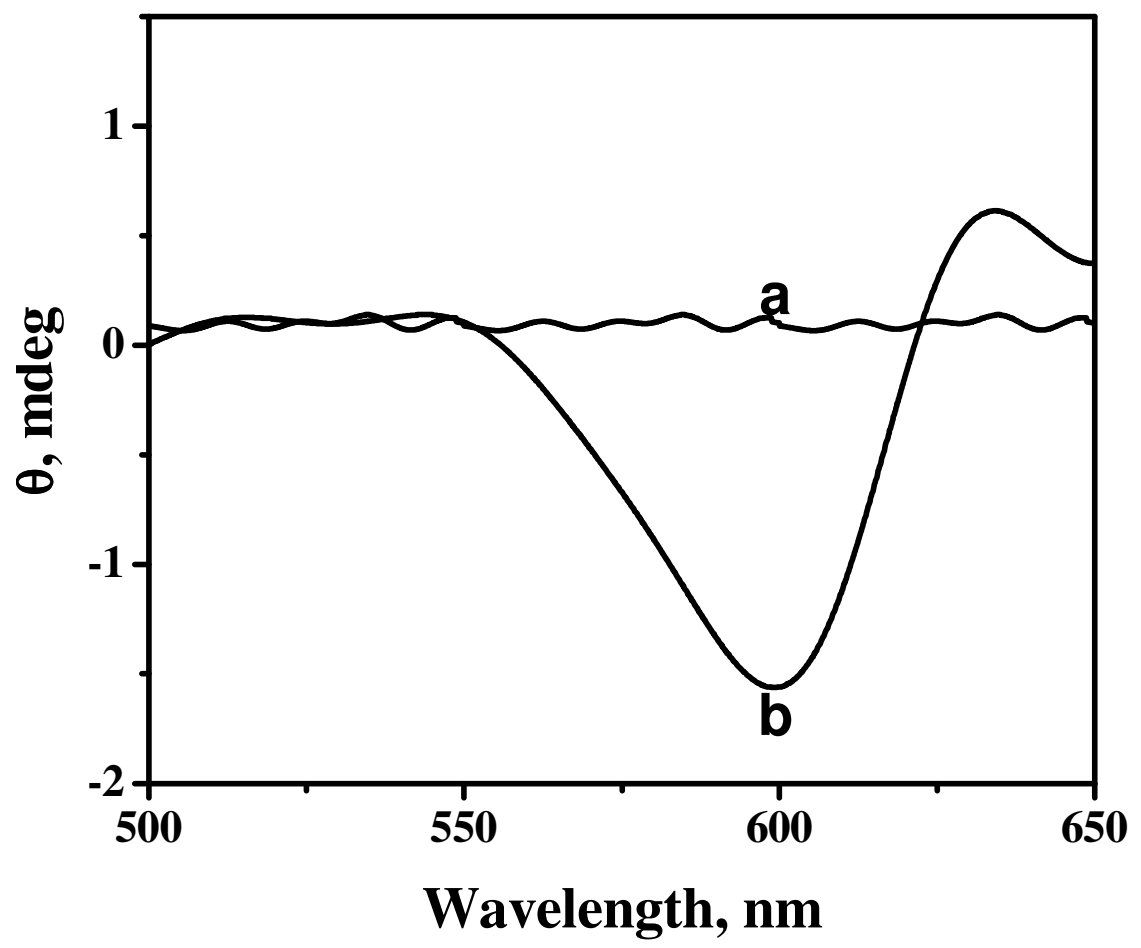

Figure S3. Circular dichroism (CD) spectra of SQ in absence and presence of BSA. a) SQ alone $(6.46 \mu \mathrm{M})$ and b) induced CD spectrum of SQ in presence of BSA (7.44 $\mu \mathrm{M})$. 


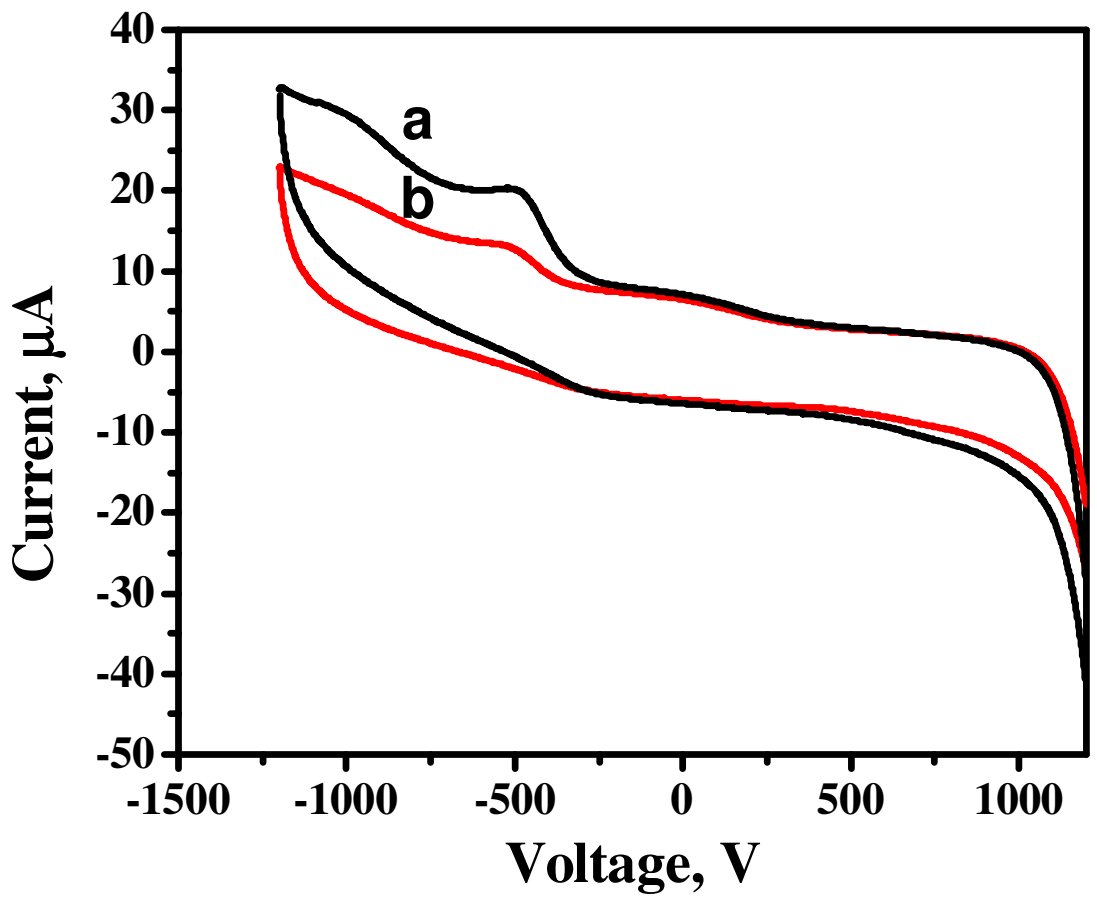

Figure S4. Cyclic voltammogram (CV) of SQ. a) SQ alone (0.2 $\mathrm{mM})$ b) SQ in presence of BSA $(77 \mu \mathrm{M})$. Scan rate $100 \mathrm{mV} / \mathrm{s}$.

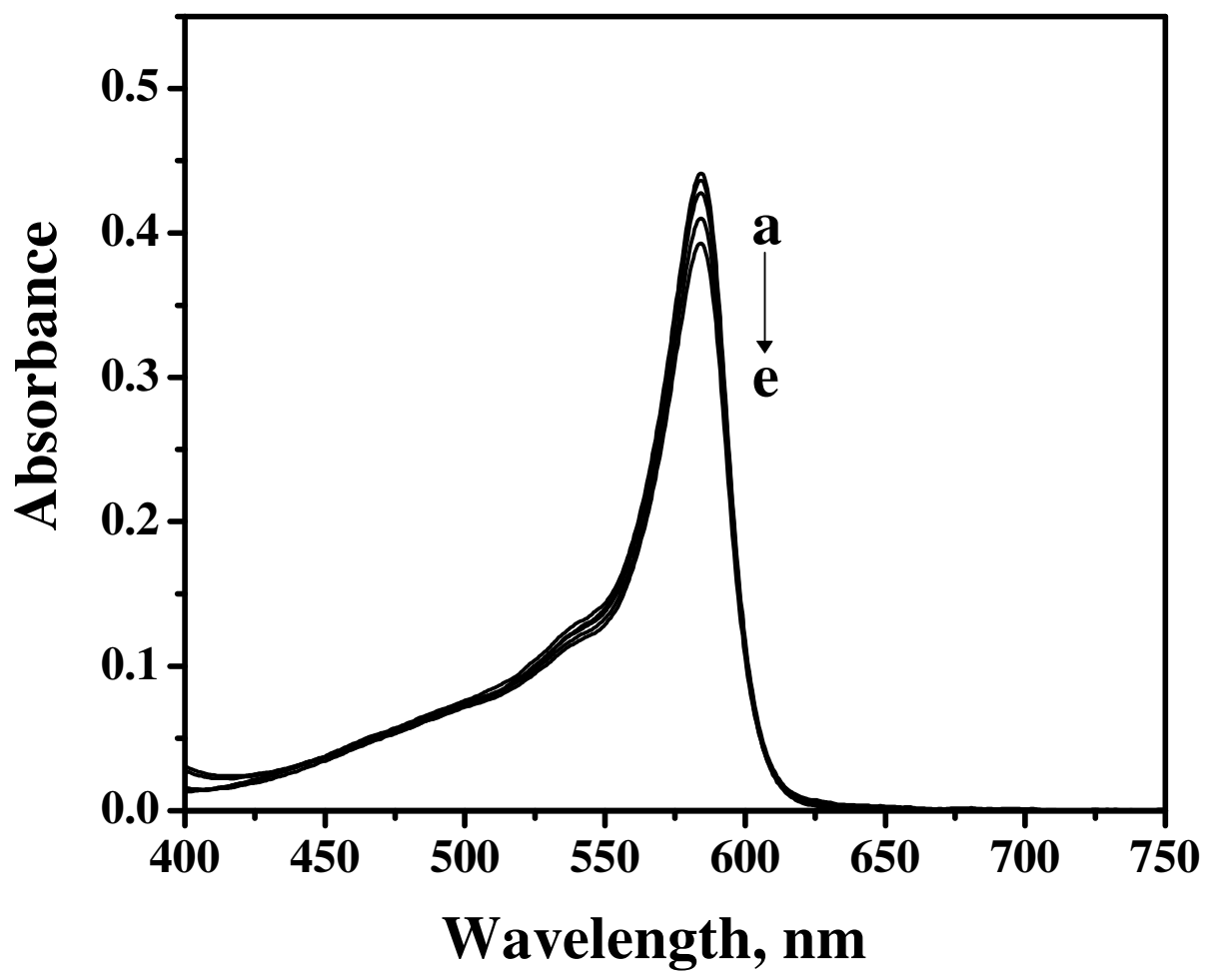

Figure S5. Effect of dansylproline (DP) concentration on the absorption spectrum of SQ $(3.0 \mu \mathrm{M})$. [DP]: a) 0.0, b) 0.16 , c) 0.30 , d) 0.44 and e) $0.6 \mathrm{mM}$. 


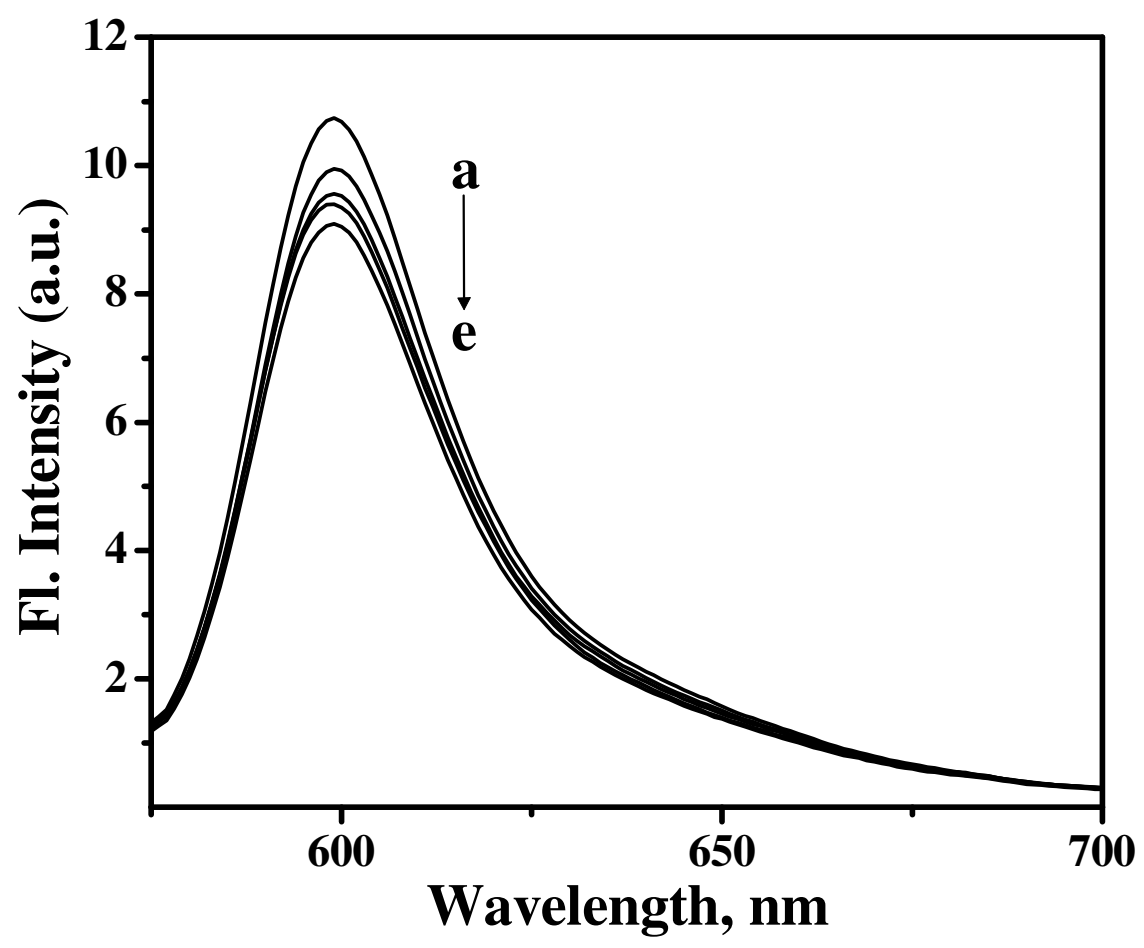

Figure S6. Effect of dansylproline (DP) concentration on the emission spectrum of SQ $(3.0 \mu \mathrm{M})$. [DP]: a) 0.0, b) 0.16 , c) 0.30 , d) 0.44 and e) $0.6 \mathrm{mM}$. Excitation wavelength, $560 \mathrm{~nm}$.

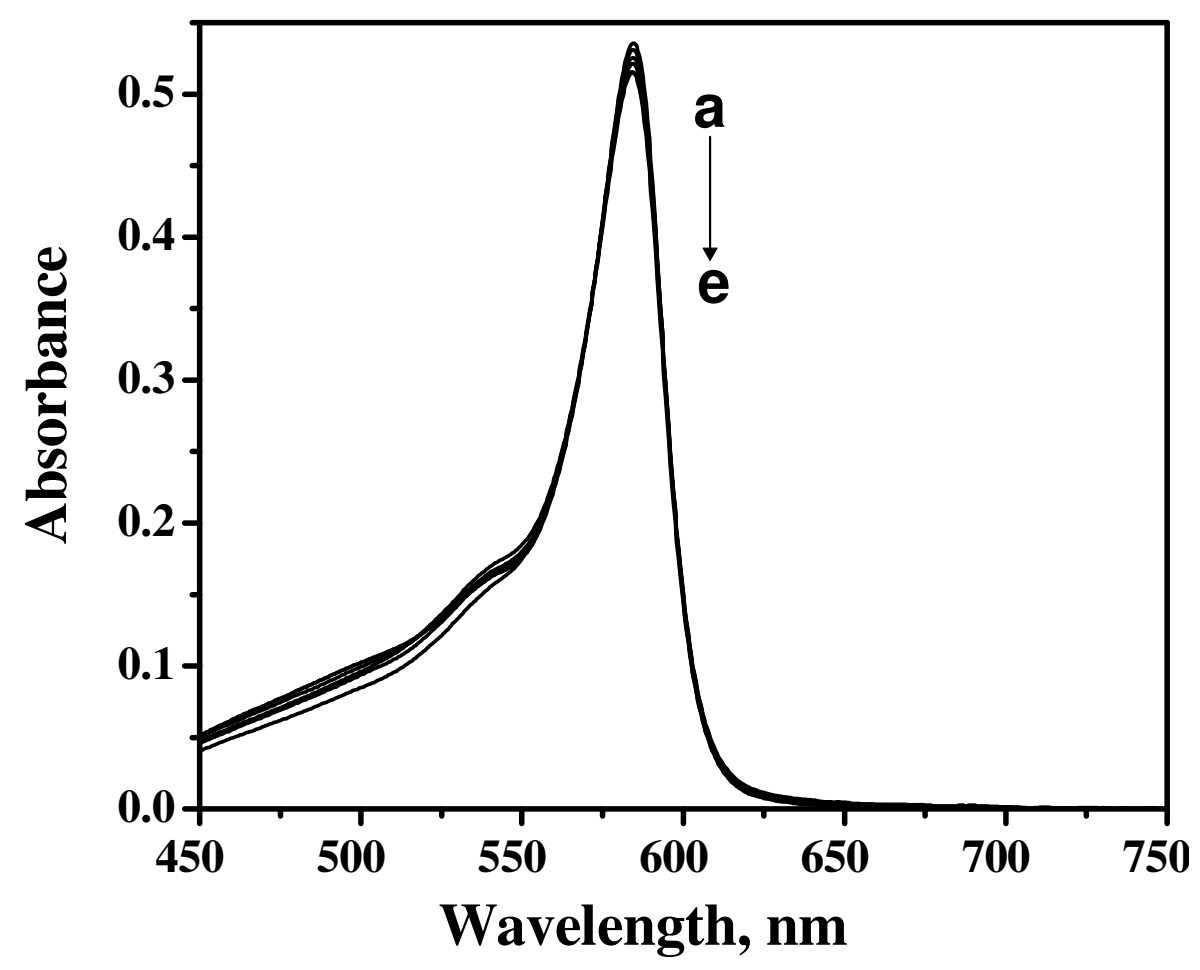

Figure S7. Effect of dansylamide (DNSA) concentration on the absorption spectrum of $\mathrm{SQ}(3.0 \mu \mathrm{M})$. [DNSA] a) 0.0, b) 0.22 , c) 0.43 , d) 0.62 and e) $0.71 \mathrm{mM}$. 


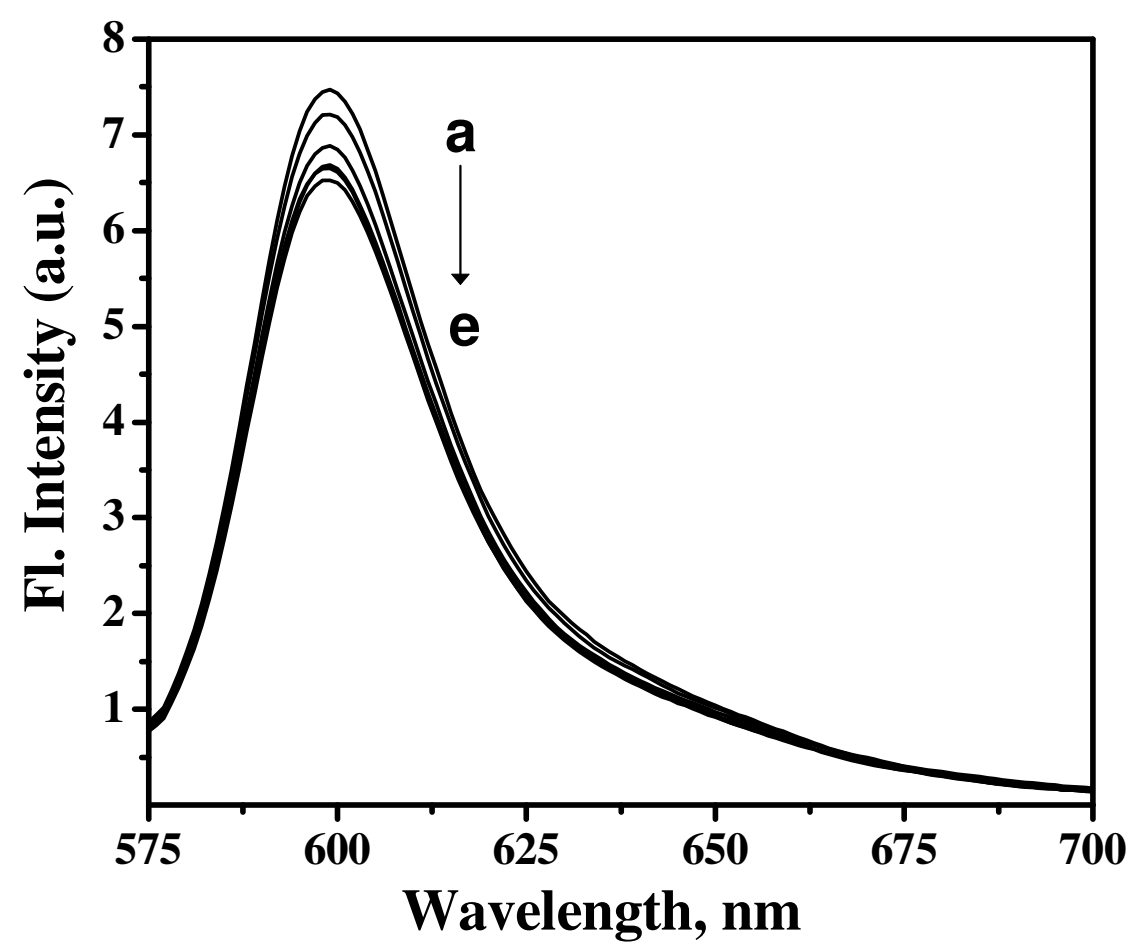

Figure S8. Effect of dansylamide (DNSA) concentration on the emission spectrum of SQ $(3.0 \mu \mathrm{M})$. [DNSA] a) 0.0, b) 0.22 , c) 0.43 , d) 0.62 and e) $0.71 \mathrm{mM}$. Excitation wavelength, $560 \mathrm{~nm}$.

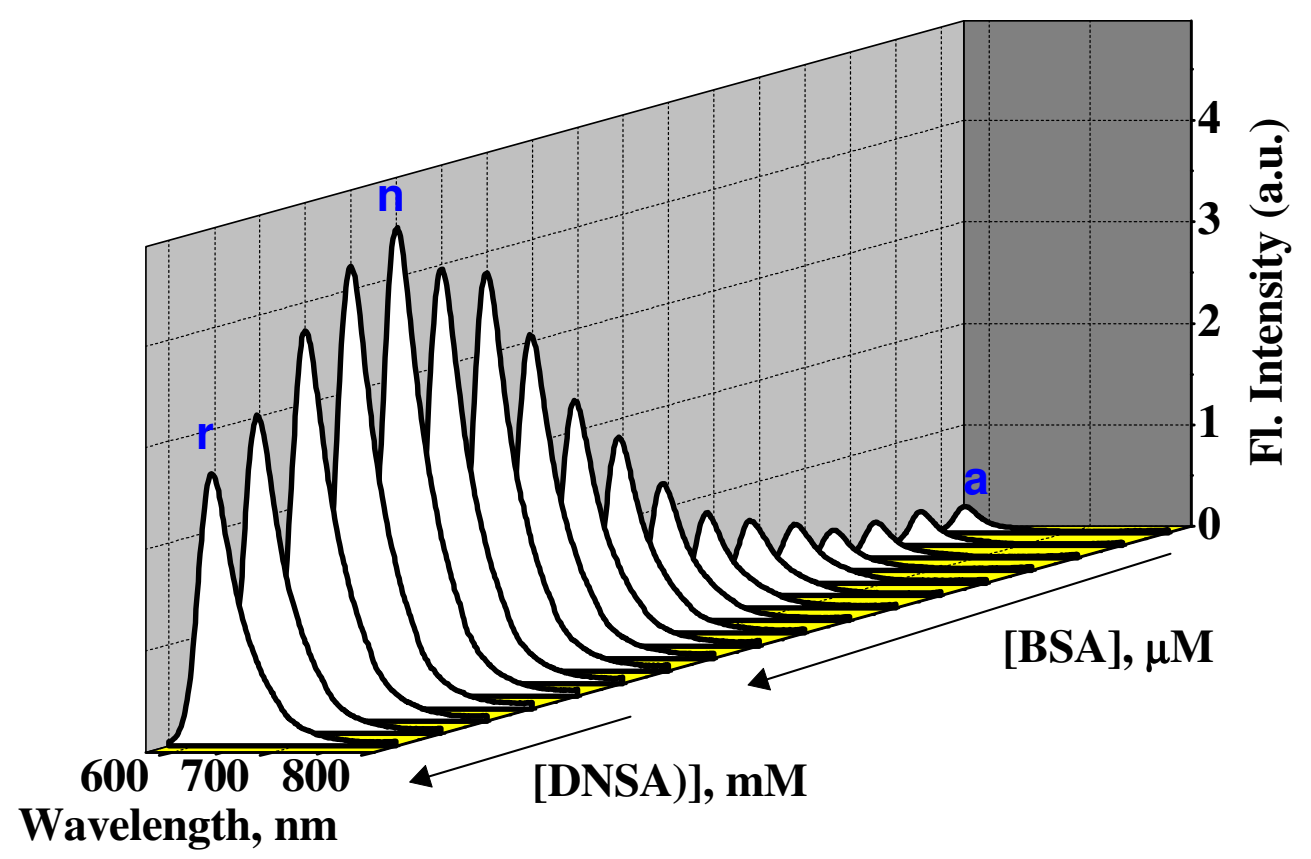

Figure S9. Effect of BSA on the fluorescence spectra of SQ $(3 \mu \mathrm{M})$ and followed by the addition of dansylamide (DNSA). [BSA] a) 0.0, b) 0.09, c) 0.19, d) 0.28, e) 0.38, f) 0.75, g) $1.13, \mathrm{~h}) 1.50$, i) 1.88, j) 2.0 , k) 2.82 , l) $3.7, \mathrm{~m}) 5.64, \mathrm{n}) 7 \mu \mathrm{M}$ and [DNSA] n) 0.0, o) 0.22, p) 0.42 , q) 0.62 , r) $0.71 \mathrm{mM}$. Excitation wavelength, $560 \mathrm{~nm}$. 